\title{
Subcutaneous and intravenous infusions were similarly well accepted, safe, and feasible in older patients with dehydration
}

Slesak G, Schnürle JW, Kinzel E, et al. Comparison of subcutaneous and intravenous rehydration in geriatric patients: a

randomized trial. J Am Geriatr Soc 2003;51:155-60.

\section{QUESTION: In older patients with mild to moderate dehydration, how do subcutaneous (SC) and intravenous (IV) infusions compare for acceptance, feasibility, and adverse effects?}

\section{Design}

Randomised \{allocation concealed\} $\uparrow^{*}$ unblinded*, trial with median 6 days duration of fluid use.

\section{Setting}

Geriatric wards of a hospital in Tübingen, Germany.

\section{Patients}

96 patients who were $\geq 60$ years of age (mean age $85 \mathrm{y}$, $70 \%$ women), had mild to moderate dehydration, and needed parenteral fluids. Exclusion criteria included infectious and allergic skin diseases, generalised oedema, acute myocardial infarction, manifest or imminent shock, IV drug requirement, and total parenteral nutrition. Follow up was $92 \%$.

\section{Intervention}

Patients were allocated to receive SC $(n=48)$ or IV $(n=48)$ infusions of half normal saline glucose solutions (containing glucose 5\% and half isotonic electrolytes). The amount and duration of fluid therapy depended on medical necessity.

\section{Main outcome measures}

Using Likert-like scales (scores ranging from 1 [very good] to 6 [very bad]), patients reported the discomfort of the received fluid therapy, and nurses and doctors separately reported overall feasibility of therapy based on practical implementation and occurrence of complications. Adverse effects were also recorded.

\section{Main results}

Analysis was by intention to treat. The SC group used a lower volume of fluids than the IV group (median 750 $\mathrm{ml} / \mathrm{d} v 1000 \mathrm{ml} / \mathrm{d}, \mathrm{p}=0.002)$. In 13 patients, therapy had to be changed from SC to IV infusion. In 17 patients, therapy had to be changed from IV to SC infusion. Median scores $(25 \%$ and $75 \%$ quantiles) on the Likert-like scales showed that the SC and IV groups did not differ for patients' discomfort (2 [2 to 3] v 2 [1 to 3], respectively; $\mathrm{p}=0.25$ ) or nurses' feasibility ( 2 [2 to 3$] v 2$ [2 to 3.25], respectively; $\mathrm{p}=0.80$ ), but doctors scored the feasibility better in the SC than IV group (2 [1.25 to 2] $v$ 2 [2 and 3.88], respectively; $\mathrm{p}=0.011$ ). The $\mathrm{SC}$ and IV groups did not differ for rates of systemic side effects (which were infrequent) or mild or major local side effects.

\section{Conclusion}

In older patients with mild to moderate dehydration, subcutaneous and intravenous infusions were similarly well accepted, safe, and offered similarly easy feasibility.

*See glossary.

†Information provided by author.

\section{Source of funding: no external funding.}

For correspondence: Dr G Slesak, Tropenklinik Paul-LechlerKrankenhaus, Tübingen, Germany guentherslesak@web.de

\section{COMMENTARY}

Hypodermoclysis, the SC infusion of fluids, has been used successfully in the palliative care setting. ${ }^{1}$ However, it remains an underused method of fluid delivery in dehydrated older adults. The randomised trial by Slesak $e t$ al is the first to directly compare the tolerability and safety of SC and IV rehydration in elderly patients who are in hospital.

The trial has several limitations. The psychometric properties of the scoring system used to measure outcomes are not described; thus, it is difficult to interpret what constitutes a clinically meaningful difference with these scores. Furthermore, almost a third (30/96) of the patients crossed over from 1 form of rehydration to the other, so the trial is more about a comparison of initial therapy. Overall, however, the trial follows decisions that would be used in routine clinical practice, and the reasons for crossovers are sensible. In the study by Slesak $\mathrm{et}$ al, the most common reason patients were switched from SC to IV catheters was to provide parenteral medication.

SC infusion has advantages over the IV route. ${ }^{2-3}$ Patients with poor peripheral venous access or who pull out their IV catheters can be given SC infusions as in this trial. SC catheters are easier to set up and may require different resources; in this trial, physicians were required to insert IV lines while nurses inserted the SC lines. Hypodermoclysis can be used at sites that the patient cannot easily reach (eg, back and thigh), which is helpful when the patient is agitated and prone to removing lines.

Adverse effects were infrequent overall, and were comparable with SC and IV therapy. Systemic adverse effects included fluid overload and hyponatraemia, and local reactions included swelling at the infusion site, cellulitis, and pain.

Hypodermoclysis may be a valuable alternative to IV fluid therapy for older patients with poor venous access or agitation.

Sudeep Gill, MD Kunin-Lunenfeld Applied Research Unit Toronto, Ontario, Canada

1 Steiner N, Bruera E. Methods of hydration in palliative care patients. $J$ Palliat Care

2 Rochon PA, Gill SS, Litner J, et al. A systematic review of the evidence for hypodermoclysis to treat dehydration in older people.J Gerontol A Biol Sci Med Sci 1997;52:M169-76.

3 Dasgupta M, Binns MA, Rochon PA. Subcutaneous fluid infusion in a long-term care setting. JAm Geriatr Soc 2000;48:795-9. 